\title{
Comparte tu voz
}

\author{
Share your voice
}

Yobana Castillo Sánchez"

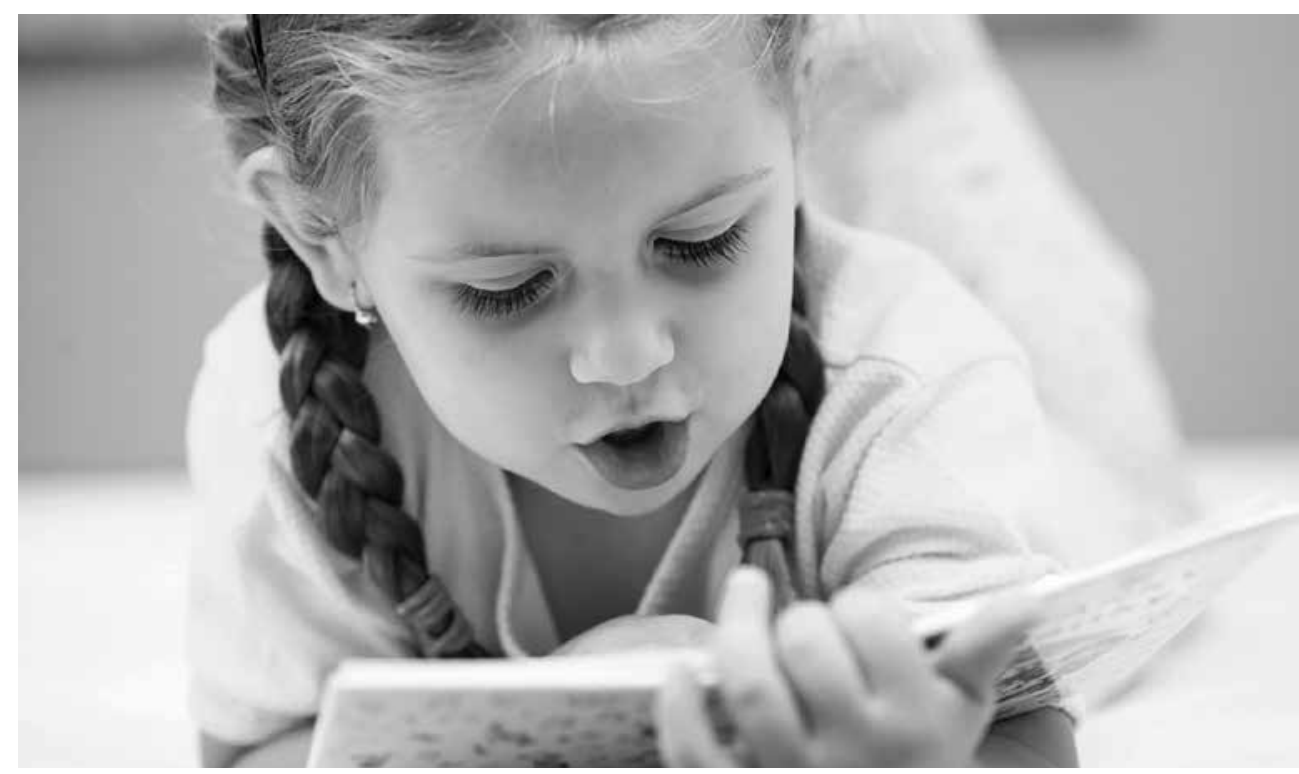

\section{Resumen}

Teniendo en cuenta la importancia de la lectura en los procesos de enseñanza-aprendizaje se desarrolló la presente investigación, la cual está orientada a identificar los aspectos metodológicos de la lectura en voz alta que contribuyeron en la formación de lectores autónomos del curso 602 J.M. de la Institución Educativa Distrital Misael Pastrana Borrero de la ciudad de Bogotá. Esta investigación ofrece la oportunidad de mostrar los alcances, los aciertos, las dificultades y la evaluación del proceso de implementación de una secuencia didáctica de lectura en voz alta y su incidencia en la formación de lectores autónomos. Se describen los resultados del trabajo de campo y los hallazgos del ejercicio investigativo. El documento finaliza con la presentación de las conclusiones y recomendaciones, las cuales sugieren un conjunto de estrategias para la promoción de la lectura en voz alta.

Palabras clave: lectura en voz alta, lectores autónomos.

Citar este artículo como: Castillo Sánchez, Y. (2019). Comparte tu voz. Revista Papeles, 11(21), 66-77.

Fecha de recibido: marzo 15 de 2019 • Fecha de aceptación: mayo 30 de 2019

* Normalista Superior de la Escuela Normal Superior Valle de Tenza. Licenciada en Lengua Castellana y Comunicación de la Universidad de Pamplona. MA en Educación de la Universidad Externado de Colombia. Estudiante del Doctorado en Educación de la Universidad Internacional Iberoamericana de México. Docente de la Secretaria de Educación de Bogotá. Correo electrónico: yobisna26@hotmail.com 


\begin{abstract}
Abtract
Taking into account the importance of reading in the teaching-learning process, this research aimed to identify methodological aspects of reading aloud that contribute to the formation of autonomous readers of the 602 J.M. of the Misael Pastrana Borrero District Educational Institution in Bogotá. This research offers the opportunity to show the scope, successes, difficulties and evaluation of the process of implementing a didactic sequence of reading aloud and its impact on the formation of autonomous readers. The results of the field work and the findings of the research exercise are widely described. The document ends with the presentation of the conclusions and recommendations that suggest a set of strategies for the promotion of reading aloud.
\end{abstract}

Keywords: reading aloud, autonomous readers.

\title{
Introducción
}

Una de las finalidades básicas de la educación es la preparación de los estudiantes para que lleguen a ser ciudadanos capaces de comprender e interpretar la realidad, de valorarla, tomar decisiones e intervenir en ella. Por tanto, el sistema educativo ha de ofrecer a los niños herramientas que permitan la resolución de los problemas, el conocimiento de la realidad y la actuación que sobre ella plantean. Una de estas herramientas es la lectura, en su papel fundamental de construcción del aprendizaje.

\section{Objetivo}

Esta investigación estuvo orientada a identificar los aspectos metodológicos de la lectura en voz alta que contribuyen en la formación de lectores autónomos del curso 602 J.M. de la Institución Educativa Distrital Misael
Pastrana Borrero de la ciudad de Bogotá. Esta investigación ofrece la oportunidad de mostrar los alcances, los aciertos, las dificultades y la evaluación del proceso de implementación de una secuencia didáctica de lectura en voz alta.

\section{Planteamiento del problema}

Resulta preocupante que con frecuencia en las aulas de clase se presenta la lectura como una actividad individual de decodificación que termina convirtiéndose en un ejercicio de rutina, tedioso y carente de sentido para los estudiantes, sin más rigor que el de cumplir con los objetivos de la clase de castellano. Situación que repercute en la actitud de los estudiantes frente a dicha actividad, generando desinterés y apatía. Tironi y Molina (2010), citando a Levy (2009), señalan que
Una de las principales razones aducidas es que las escuelas adoptan esquemas lectores demasiados rígidos que dificultan el disfrute y el compromiso significativo con la literatura, ya que esta es utilizada de un modo meramente utilitario. En este sentido, los niños apreciarían la literatura exclusivamente como una herramienta para aprender la mecánica de la decodificación de textos y no como una actividad asociada al goce (p. 13). 


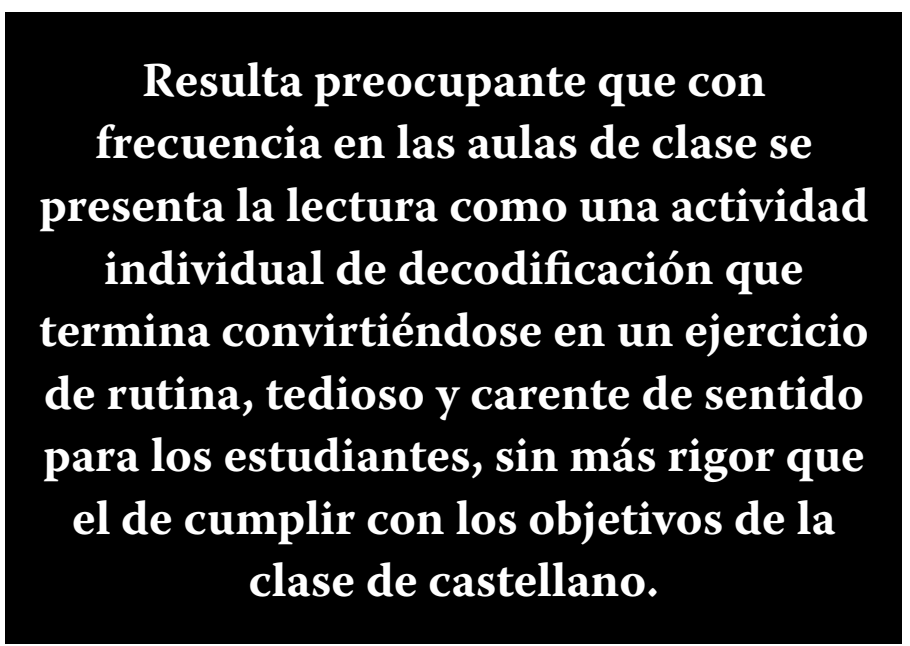

Con relación a los hábitos de lectura de niños y jóvenes entre 5 y 17 años:

El 66\% de jóvenes entre los 12 y 16 años que señaló que leer le parece aburrido. En esta línea, el 83\% de los niños y jóvenes encuestados afirmó que las razones que lo remiten a leer libros son netamente académicas, y sólo el $17 \%$ restante acude a la lectura de literatura por entretenimiento; esto se relaciona con el $54 \%$ de los estudiantes que afirmó que le gusta leer, pero no tiene acceso a libros que sean acordes a su edad, en otras palabras, que respondan a sus intereses (Fundalectura, Ministerio de Cultura, 2006).

Esta problemática no es ajena a los estudiantes del grado sexto de la Institución Educativa Distrital Misael Pastrana Borrero, quienes, por la carencia de ejercicios de lectura en voz alta en el aula, el poco acompañamiento de los padres de familia en el proceso de aprendizaje y la evidente desmotivación por la lectura ven disminuida su capacidad de socialización, de expresión y argumentación oral, la comunicación y la construcción de significado. Situaciones que se ven reflejadas en la poca participación oral en clase y en un escaso desarrollo de las competencias comunicativas en las evaluaciones realizadas por los estudiantes. Ahora,
Justamente por la importancia que tiene el lenguaje como herramienta para la vida, resulta preocupante para la actual administración los resultados obtenidos por los estudiantes del distrito capital en pruebas como Comprender y Saber que evidencian, por ejemplo, que el $16 \%$ de los estudiantes de quinto grado de los colegios oficiales está en un nivel insuficiente, $46 \%$ en el mínimo, apenas $31 \%$ en satisfactorio y solo el $8 \%$ en el avanzado (Gúzman, Varela y Arce, 2010, p. 7).

Lo anterior pone en evidencia la necesidad de abordar desde el aula la lectura en voz alta para que favorezca el desarrollo de competencias del lenguaje de los estudiantes. Aunque se han ejecutado proyectos para el fomento de la lectura a nivel distrital en la ciudad de Bogotá, contexto en el cual se desarrolla la presente investigación, como el Proyecto Institucional de Lectura, Escritura y Oralidad (PILEO) y el de Lectura, Escritura y Oralidad (LEO), que han sentado un precedente sobre la importancia de la lectura, el tema de la lectura en voz alta como estrategia metodológica ha sido poco trabajada y cualificada.

Cabe señalar el importante papel que desempeñan los docentes en la formación de hábitos de lectura, como lo indica una encuesta de consumo del DANE que asegura que de "las personas de 12 años y más que saben leer y escribir, el $34,5 \%$ de la población afirmó que fueron los profesores quienes les crearon el hábito de la lectura" (DANE , 2013), el cual constituye el porcentaje más alto, seguido de la iniciativa propia, con un $29,1 \%$ (p. 7).

Lo expuesto sugiere cómo los docentes deben reconocer las bondades de la lectura en voz alta e integrarla a nuestro quehacer pedagógico, de manera que esta práctica retome su posicionamiento en los procesos de enseñanza-aprendizaje, puesto que representa una herramienta efectiva para potenciar las habilidades comunicativas, motivar a los estudiantes a la lectura y contribuir en su formación como lectores autónomos. 


\section{Diseño metodológico}

El desarrollo de este estudio se enmarcó en el enfoque de investigación sociocrítico, que "tiene como objetivo promover las transformaciones sociales, dando respuestas a problemas específicos presentes en el seno de las comunidades, pero con la participación de sus miembros" (Alvarado y García, 2009, p. 6), que es pertinente para la presente investigación, dado que al identificar la carencia de prácticas de lectura en el aula se plantea la lectura en voz alta como una estrategia para la formación de lectores autónomos, generando en los estudiantes el agrado por la lectura en la cual fueron directos participantes.

Las categorías definidas para este estudio fueron: aspectos metodológicos de la lectura en voz alta, entendida como una modalidad de lectura que hace uso de la voz del lector dirigida a un público que participa de esta a través de la escucha, y formación de lectores autónomos, que hace referencia a los procesos individuales o colectivos que conducen a crear nuevos lectores y establecer hábitos de lectura.

\section{Análisis de la información y hallazgos}

En este apartado se describen los hallazgos o resultados de esta investigación, que se desarrolló en cuatro fases: fase de caracterización de la población, fase de diseño de la propuesta, fase de intervención o aplicación de la propuesta y fase de evaluación.

\section{Fase de caracterización}

En esta fase se aplicó un cuestionario semiestructurado de caracterización para recoger información personal y académica y para identificar las concepciones que tienen los estudiantes de la muestra acerca de la lectura en voz alta y los hábitos de lectura en la casa y el colegio.

Frente la pregunta "¿Cuánto tiempo al día dedicas a la lectura?", el 53,3 \% de los estudiantes manifestaron que el tiempo que dedican a la lectura es 30 de minutos, seguido de 10 minutos (con un $33,3 \%$ ) y finalmente de una hora $(13,3 \%)$.

Al preguntar a los estudiantes por los adultos que con mayor frecuencia les leen en voz alta, el 66,7 \% manifestaron que son los profesores, seguido de nadie (con un 23,3\%), sus padres (con un $10 \%$ ) y finalmente los bibliotecarios
(0.0 \%). El porcentaje referido a los profesores concuerda con los resultados de la encuesta de consumo del DANE del año 2013, que asegura que de "las personas de 12 años y más que saben leer y escribir, el $34,5 \%$ de la población afirmó que fueron los profesores quienes les crearon el hábito de la lectura".

$\mathrm{Al}$ interrogar sobre lo que más leen los estudiantes, se halló que el 50 \% leen cuentos, el $30 \%$ historietas y el 10 noticias y artículos de revista. El porcentaje mayor, los cuentos, fue tenido en cuenta en la construcción de la secuencia didáctica de lectura en voz alta.

Otro aspecto importante en el que se indagó fue la cantidad de libros con los que cuenta cada estudiante en su casa. El 40 \% manifies$\tan$ que tienen en la casa entre 5 y 10 libros, el $30 \%$ entre 10 y 30 libros, el $23 \%$ más de 50 libros, y el $6 \%$ entre 30 y 50 libros. El porcentaje más alto, que hace referencia a la mínima cantidad de libros con los que cuenta un estudiante en su casa, puede ser el resultado de las condiciones socioeconómicas de las familias, ya que el $76 \%$ dicen pertenecer al estrato 2 , y el $74 \%$ de los padres de familia señaló el bachillerato como último nivel de escolaridad. 
Finalmente, se preguntó a los estudiantes por las actividades que desarrollan en la biblioteca. De estas, 3,3\% manifiestan que la actividad que desarrollan en la biblioteca es leer, seguido de leer y escribir con $20,8 \%$; luego, con el mismo porcentaje de $16,7 \%$, leo y juego ajedrez; $8,3 \%$ dicen que no hacen ninguna actividad y $4,2 \%$ hacer tareas.

Se diseñó y aplicó un diagnóstico de lectura en voz alta con el objeto de identificar el nivel de desempeño de los estudiantes del curso 602 J.M. en las características observables de la lectura en voz alta. Tomando una escala valorativa cualitativa, para determinar el grado de presencia de los aspectos observables de la lectura en voz alta, que son el volumen, entendido como la intensidad (fuerza) de la voz; la dicción, como la forma de articular o de pronunciar cada palabra; la entonación, entendida como el ascenso o descenso de los tonos, es decir, la modulación de la voz; la fluidez, entendida como la velocidad con la que se pronuncian las palabras; y la puntuación, como el conjunto de signos necesarios para señalar las pausas y otros matices de sentido y entonación que se han de tener en cuenta para interpretar debidamente un texto.

Ahora, la escala valorativa cualitativa señala tres niveles: bueno, si el estudiante se desempeña en el aspecto evaluado de manera esperada; regular, si el estudiante se desempeña en el aspecto evaluado de manera inferior a lo esperado o con algunas dificultades; y deficiente, si el estudiante se desempeña en el aspecto evaluado con dificultades o no lo alcanza.

Teniendo en cuenta lo anterior, el análisis de la prueba diagnóstica de lectura en voz alta evidencia que el aspecto donde el $80 \%$ de los estudiantes se ubican en un nivel deficiente es en la puntuación, dado que no hacen las pausas; ni se evidencia la entonación y los matices de voz que indican los signos de puntuación. Por consiguiente, el lector y los oyentes le dan un sentido diferente al texto.
Es evidente la ininteligibilidad, monotonía, lentitud y apresuramiento.

El 61 \% de los estudiantes se ubican en un nivel deficiente de entonación, pues se evidencia una lectura plana, con ausencia de ascenso o descenso de los tonos, es decir, sin modulación de la voz, lo que facilita la dispersión de los oyentes.

El $55 \%$ de los estudiantes se ubican en un nivel deficiente en el aspecto relacionado con la dicción, ya que se les dificulta la correcta pronunciación de palabras, lo que genera distorsión del sentido del texto, distracción y ansiedad en los oyentes.

El $50 \%$ de los estudiantes se ubican en el nivel deficiente en el aspecto relacionado con la fluidez, puesto que desarrollan una lectura silabeada y con muchas interrupciones, con la que los oyentes se indisponen, manifiestan ansiedad e intervienen en la lectura del compañero.

El $41 \%$ de los estudiantes se ubican en el nivel deficiente en el aspecto relacionado con el volumen, dado que en el desarrollo del ejercicio de lectura en voz alta la fuerza de la voz no fue suficiente para ser escuchada por todos sus compañeros; lo que genera dispersión, ansiedad, injerencia de los compañeros e interrupción de la lectura.

En consecuencia, es apremiante que se intervenga en el proceso de lectura en voz alta de los estudiantes a través de una secuencia didáctica, que dé prioridad a los aspectos relacionados con la puntuación, la entonación y la dicción.

\section{Fase de diseño de la propuesta}

Teniendo en cuenta la información recolectada en el cuestionario de caracterización de la población y los resultados del diagnóstico de lectura en voz alta, se diseñó una secuencia didáctica de lectura en voz alta de diez sesiones, a partir del modelo de Ana Camps 
(2003, p. 41). El objetivo de esta secuencia fue fortalecer los aspectos metodológicos de la lectura en voz alta en los estudiantes del curso 602 J.M., atendiendo las características observables (dicción, volumen, fluidez, entonación y puntuación).

\section{Fase de intervención o aplicación de la propuesta}

Frente a las condiciones para el desarrollo de la lectura en voz alta, en cuanto al material, es importante reconocer la carencia de libros para trabajar esta modalidad de lectura con todos los estudiantes de un curso, además de la imposibilidad de pedir a los padres la adquisición de estos recursos. Sin embargo, la institución educativa cuenta con unas pocas colecciones de Libro al viento.

Entre los aciertos, se cuenta la selección de textos (El terror de sexto B de Yolanda Reyes y Cuentos de animales de Rudyard Kipling; ambos de la colección Libro al viento), ya que los estudiantes manifestaron en la autoevaluación el agrado por estos, como consta en algunos de los testimonios registrados por los niños en el instrumento de autoevaluación:

"me gusto aber leido el libro sobre el cuento de los animales".

"que el cuento estaba demasiado entretenido".

"cuando leimos el libro del terror de sexto B”.

"me gusto el cuento de juan el listo, fue muy chevere tambien me gusto la hoja de la lectura y me gusto leer el terror de sexto B". ${ }^{1}$

(Informes $\backslash \backslash$ Resumen de codificación por informe de nodo Nvivo, p. 8).

En términos generales, lo que más les gustó a los estudiantes en cada sesión fue la posibilidad de leer en voz alta en la clase y compartir esa

1 Así se encuentra en el original. lectura con los compañeros, como lectores y como oyentes, según lo manifestado por ellos en los formatos de autoevaluación:

"leer".

"Leer en voz alta el cuento".

"Que todos estuvimos atentos en la clase de lectura voz alta".

"todo porque es un ejercicio en grupo".

"lo que me gusto fue la practica de lectura en voz alta".

"fue que todos leimos en esta sesion de lectura en voz alta".

"que uno aprende a escuchar y a leer en voz alta".

"El silencio y la atencion de la mayoria de compañeros".

"que lei y la profe conocio mi libro".

"que hicimos una lectura en voz silenciosa y en voz alta y me emocione con la lectura". (Informes $\backslash$ Resumen de codificación por informe de nodo Nvivo, p. 17).

La secuencia didáctica se desarrolló con la metodología de trabajo colectivo. Como su nombre lo indica, orienta la enseñanza en grupo, buscando la integración de un colectivo en torno a un tema, en este caso la lectura en voz alta, donde la reunión de los esfuerzos individuales y de la colaboración entre los estudiantes son elementos importantes para el alcance del producto final. Esta metodología, junto con la modalidad de lectura en voz alta, favorece la socialización, trabajo en equipo, sentimiento comunitario y respeto hacia los demás, como lo evidencia a continuación un fragmento de los diarios de campo:

se da inicio a la lectura en voz alta del mismo cuento, durante esta lectura, todos los estudiantes escuchan atentamente al lector de turno, mantienen la vista en el libro previendo oportunamente su turno de lectura, no se presentan interrupciones significativas, cuando un lector presenta un error de dicción, uno de los 
compañeros lo corrigen de forma amable (Diario de campo, sesión 9, p. 11).

En este aspecto, los estudiantes manifestaron en los formatos de autoevaluación:

"contento, porque aprendimos mucho".

"escuchar a mis compañeros".

"contenta, porque todos participamos".

"contento, lo mejor de leer con mis compañeros".

"contenta, porque todos leemos en voz alta".

(Informes $\backslash \backslash$ Resumen de codificación por informe de nodo Nvivo, p. 180).

Los procesos pedagógicos, lingüísticos y cognitivos que se hicieron evidentes en el desarrollo de la secuencia didáctica de lectura en voz alta se describen a continuación:

Los procesos pedagógicos, entendidos como las actividades que desarrolla el docente de manera intencional con el objeto de mediar en el aprendizaje significativo del estudiante, durante la secuencia de lectura en voz alta, fueron evidentes en las acciones de motivación de la docente investigadora hacia los estudiantes para propiciar un ambiente favorable que permitió el desarrollo satisfactorio de las actividades que se planearon. Además, tuvo en cuenta los conocimientos previos de los estudiantes para favorecer la construcción del nuevo conocimiento. Así mismo, la planeación de la secuencia didáctica favoreció el procesamiento de la información para el desarrollo del aprendizaje, presente en la estructura de fases: entrada, elaboración y salida.

\section{Fase de evaluación}

En esta fase se describen los hallazgos a partir del análisis de la información y triangulación de instrumentos como: formato de autoevaluación que desarrollaron los estudiantes en cada sesión, diarios de campo, talleres de comprensión auditiva, videos de cada sesión de la secuencia y marco teórico. Todo esto fue realizado para dar cuenta del objetivo general y las categorías formuladas para este estudio: aspectos metodológicos de la lectura en voz alta y formación de lectores autónomos.

Gray (1958) señala que "para formar buenos lectores es necesario comprender la naturaleza de las capacidades y técnicas fundamentales e indispensables para la lectura"; por tanto, en las primeras cinco sesiones de la secuencia didáctica se abordaron las características observables de la lectura en voz alta (dicción, volumen, entonación, fluidez y puntuación), donde todos los estudiantes desarrollaron los ejercicios propuestos para tal fin, logrando progresivamente avances importantes, ubicando al $87 \%$ en un nivel de desempeño bueno, dado que en las últimas sesiones se presentaron pocas interrupciones, lo que demuestra la disminución significativa de falencias como la ininteligibilidad, monotonía, lentitud y apresuramiento.

En cuanto a las características observables de la lectura en voz alta en el formato de autoevaluación (en la sección "Lo que mejoré en esta sesión de lectura en voz alta en mi proceso lector fue"), los estudiantes manifestaron:

"que aprendimos apronunciar mejor".

"es importante, porque mejoro la lectura y la pronunciacion de las palabras raras".

"la voz para leer mas fuerte".

"lo que mejore es que hay que subir la voz, sentarse derecho para leer y para que la voz salga bien".

"lo que mejore fue mi entonacion de voz y el volumen y mejore mi lectura en voz alta" (Informes $\backslash \backslash$ Resumen de codificación por informe de nodo Nvivo, p. 87).

Durante las últimas cinco sesiones de lectura en voz alta, respecto a la pregunta "El libro que estoy leyendo en mi tiempo libre es", los estudiantes respondieron:

"cupido es un murcielago".

"entre pecas y lentejas". 
"el caballero de la armadura oxidada".

"Batman y sus amigos".

"por todos los dioses".

"No nacimos pa semilla, capitulo VII".

(Informes $\backslash \backslash$ Resumen de codificación por informe de nodo Nvivo, p. 56).

El $90 \%$ de los estudiantes evidenciaron, por medio del título de un libro, estar leyendo en su tiempo libre.

Entre las estrategias y actividades que desarrollan los docentes para la formación de lectores autónomos y hábitos de lectura, se encuentra la lectura en voz alta como la más importante, ya que esta "constituye el mejor estímulo para fomentar el gusto por la lectura en cualquier lugar del mundo donde se realice: el hogar o el aula. Es el catalizador para que todo niño quiera leer por sí mismo" (Trelease, 2012, p. 41). Lo que más hacen los docentes para favorecer estos procesos (según lo manifestado por ellos mismos como respuesta a la pregunta "¿Qué actividades o estrategias desarrolla en su práctica docente para motivar a sus estudiantes a leer?", en un cuestionario semiestructurado que se les realizó) es:

"Seguir la lectura en textos guía mientras yo les leo en voz alta, crear historias cortas a partir de imágenes, resaltar palabras desconocidas para buscar significado y leer en voz alta por turnos".

"Lectura de cuentos mentalmente en grupo y lectura de fragmentos de cuentos en voz alta".

(Informes $\backslash \backslash$ Resumen de codificación por informe de nodo Nvivo, p. 168).

Esto guarda mucha relación con lo manifestado por los estudiantes en el cuestionamiento "Las actividades que desarrollan mis profesores para motivarme a leer son":

"español nos pasa los libros en forma ordenada y leemos en forma ordenada en voz alta y en lectura silenciosa". "que las profes nos leen en voz alta y eso me motiva mucho".

"ponerme a leer para mejorar y eso se llama lectura en voz alta".

"en la clase de español a leer en voz alta".

(Informes $\backslash \backslash$ Resumen de codificación por informe de nodo Nvivo, p. 171).

"La lectura es una experiencia de la sensibilidad", como dice Larrosa (1998). Así pues, son muchos los sentimientos, sensaciones y emociones que despierta la lectura. Por eso,

Decimos que leer es como amar, soñar o viajar porque de pronto, desde nosotros, emerge una historia entera. Personas que no conocíamos se cristalizan en imágenes perfectamente delineadas. A veces también llegamos a países o lugares desconocidos. Todos los acontecimientos, aventuras y disputas posibles son -predecible o impredeciblementedevelados en la medida que vamos leyendo: sentimos dolor, sufrimiento, alegría, paz... Todo eso está en nuestra relación con la lectura (Sánchez, 2006).

Ante la pregunta "Los sentimientos, emociones y sensaciones que experimento cuando leo en voz alta son", los estudiantes dijeron:

"placer, tranquilidad, descanso".

"placer, descanso, alegría"

"descanso, tristeza, satisfacción".

(Informes $\backslash \backslash$ Resumen de codificación por informe de nodo Nvivo, p. 171).

Lo que resulta ser un buen indicador de lector autónomo, ya que al conocer distintas clases de libros el lector se dará cuenta que leer no es solamente estudiar un texto escolar, sino muchas más. Algo que es divertido, pero no solo es divertido, sino que, además, le permite una mirada más amplia hacia sí mismo y hacia el mundo (Vega, 1995, p. 23).

Ahora, al preguntar a los estudiantes "Las sesiones de lectura en voz alta hicieron que 
me interesara más por leer en mi tiempo libre", estos respondieron que:

"si, porque la lectura en voz alta me motivo a leer sobre cosas interesantes".

"si, porque ahora leo mejor y me gusta mas".

"si, a veces en ves de quedarme viendo television prefiero leer".

"si, porque no e dejado de leer en mi casa porque es un libro chevere".

"si, porque todo puedo mejorarlo leyendo siempre".

(Informes $\backslash \backslash$ Resumen de codificación por informe de nodo Nvivo, p. 194).

Este es otro indicador importante del lector autónomo, puesto que "el gusto se adquirirá a través de repetidos encuentros agradables con los libros, después de haber entrado en la lectura con libertad y por decisión propia, cuando se lleva a comprender, gozar y reflexionar" (Vega, 1995). En este sentido, ante la pregunta "Las razones para querer leer un libro en su tiempo libre", los estudiantes manifestaron:

"el de Badi Balastro de pasteleria porque quiero ser pastelero".

"la guerra mundial z me gustaria conocer las armas de esos tiempos".

"el libro troll porque es de comedia".

"de la bella durmiente, porque me gustan los libros de amor".

"wiguetta manga o el mesias manga me parece interesante porque trata de una historieta de jesus con personajes animados". "el caballero de la armadura oxidada, porque me dicen que es muy bueno".

"El país más hermoso del mundo porque mi primo lo leyo y dice que es muy bueno".

(Informes $\backslash \backslash$ Resumen de codificación por informe de nodo Nvivo, p. 81).

Resultados que contrastan positivamente con el desarrollo de la investigación, ya que al finalizar la secuencia didáctica se preguntó a los estudiantes "Antes de iniciar las sesiones de lectura en voz alta”, y ellos respondieron:

Leía algún texto en mi casa.

Leía el libro en mi casa.

$\square$ Leía sobre en la biblioteca.

No leía nada.

El $86 \%$ de los estudiantes señaló que no leía nada, mientras que el $14 \%$ indicó que leía algún texto en la casa.

Por otro lado, caracterizar la población objeto del estudio permitió que se particularizaran y se previeran situaciones relacionadas con la lectura, como presencia o carencia de hábitos, disponibilidad o carencia de recursos, intereses o inclinación hacia un tipo de texto o temática.

Finalmente, diagnosticar el nivel de dominio de las características observables de la lectura en voz alta y comprensión auditiva permitió señalar un punto de partida para el diseño y puesta en marcha de la intervención pedagógica; en este caso, la secuencia didáctica.

\section{Conclusiones}

De la aplicación y análisis de los instrumentos de recolección de información de la presente investigación surgieron las siguientes conclusiones y recomendaciones que dan respuesta a la pregunta de investigación " ¿Cómo formar lectores autónomos del curso 602 J.M. de la
Institución Educativa Distrital Misael Pastrana Borrero, a través de la modalidad de lectura en voz alta?"

- Reconocer que la modalidad de lectura en voz alta es una estrategia efectiva para la 
formación de lectores autónomos, ya que como lo indica un experto en el tema, Jim Trelease (2012), condiciona el cerebro del estudiante para que asocie la lectura con el placer, crea las bases del conocimiento, construye vocabulario y ofrece un modelo lector.

- Fortalecer en los estudiantes las características observables de la lectura en voz alta (dicción, volumen, entonación, fluidez y puntuación) abre la posibilidad de despertar el gusto por la lectura y por consiguiente aporta en su formación como lector autónomo.

- Validar la modalidad de lectura en voz alta como una estrategia pedagógica que desarrollan principalmente los docentes de castellano, para motivar a los estudiantes a leer y formarlos como lectores autónomos, y que es ampliamente reconocida y valorada por los mismos.

- Reconocer la modalidad de lectura en voz alta como una estrategia que posibilita la comprensión auditiva y en consecuencia favorece el desarrollo de la comprensión lectora.

- Valorar el aporte de la modalidad de lectura en voz alta en los procesos de socialización y convivencia escolar en el aula, al posibilitar un modelo de comunicación basado en la escucha.

- Reconocer el papel de los docentes en la formación de lectores autónomos al dinamizar acciones pedagógicas como la lectura en voz alta conducentes a este fin.

- Validar la modalidad de lectura en voz alta como una actividad que pueden desarrollar todos los estudiantes sin afectación por sentimientos de ansiedad o presión por leer en público, pues, a diferencia de lo planteado por los expertos internacionales en el tema, que sugieren que esta sea desarrollada por un adulto, la experiencia en esta investigación demuestra que vivir en un país pluriétnico y multicultural (como en el que viven nuestros estudiantes) no afecta tales procesos de aprendizaje.

\section{Recomendaciones}

Teniendo en cuenta las conclusiones que tuvieron lugar al abordar los resultados de la presente investigación, se hace necesario presentar recomendaciones que contribuyan a la promoción de la modalidad de lectura en voz alta, como una estrategia para favorecer en los estudiantes el gusto por la lectura.

Para las instituciones educativas:

- Reconocer las bondades de la lectura en voz alta, es necesario retomar esta modalidad en las aulas de clase, como una estrategia efectiva para incentivar en los estudiantes el gusto por la lectura y favorecer la formación de lectores autónomos.

- Adquirir colecciones de libros de literatura para la totalidad de los estudiantes de un curso, de acuerdo con las edades e intereses, para desarrollar jornadas de lectura en voz alta, donde todos los estudiantes sean activos participantes.

- Acondicionar espacios en las aulas de clase donde los libros de literatura sean de fácil acceso a los estudiantes, para favorecer la manipulación y el acercamiento espontáneo a los mismos.

- Promover el uso de la biblioteca como un espacio de interacción con los libros, donde se facilite el acceso y se favorezca la buena relación de los estudiantes con los libros.

- Desarrollar jornadas intencionales y planeadas de lectura en voz alta, para favorecer la interacción de docentes y estudiantes de diferentes cursos y niveles.

Para los docentes:

- Identificar los intereses de sus estudiantes en cuanto a la literatura, para hacer una 
buena selección de los textos para leer en voz alta.

- Promover la lectura en voz alta, leyendo para sus estudiantes y permitiendo que los estudiantes lean para sus compañeros.

- Desarrollar con los estudiantes actividades individuales y colectivas, para fortalecer las características observables de la lectura en voz alta (dicción, volumen, entonación, fluidez y puntuación).

- Promover espacios en la clase para que los estudiantes compartan con sus compañeros los libros que libremente leen en su tiempo libre.
Para los investigadores interesados en el tema:

- Indagar sobre la incidencia de las condiciones socioculturales que favorecen el ejercicio de la lectura en voz alta en el contexto particular de Bogotá.

- Desarrollar un estudio a largo plazo que dé cuenta del impacto de la lectura en voz alta en los procesos cognitivos de los estudiantes.

- Evaluar el aporte de la lectura en voz alta en los procesos de socialización y convivencia escolar.

\section{Referencias}

Alvarado, L., \& Garcia, M. (2009). Características mas relevantes del paradiga socio-critico: su aplicacion en investigaciones de educacion ambiental y de enseñanza de las ciencias. Sapiens , 6.

Amado, E. (2003). Hacia una didáctica social: la formación del lector. México D.F. : IV Congreso Nacional de Didáctica de la Lengua y la Literatura.

Arzola, E. G. ( 1975). Lengua y Literatura. La Habana: Editorial pueblo y Educación.

Betancourt, A. M. (2007). El taller educativo. Bogotá: Cooperativa Editorial Magisterio.

Blume, A. N. (1899). Organizacion de las escuelas publicas de Bogotá. El maestro de escuela, 90-161.

Camps, A. (2003). Secuencias didacticas para aprender a escribir. España: Editorial GRAÓ.

Cardona, J. G. (1955). Pénsumes colombianos de enseñanza secundaria, 1887-1955. Medellin: Imprenta Departamental de Antioquia.

Cassany, D. (2007). Luces y sombras de la lectura en voz alta. Peonza, 21.32.

Cavallo G., C. R. (2012). Historia de la lectura en el mundo occidental. Mexico: Prisa Ediciones.
Centro Virtual Cervantes. (1997). Centro Virtual Cervantes. Obtenido de Centro Virtual Cervantes: http://cvc.cervantes.es/ ensenanza/biblioteca_ele/diccio_ele/diccionario/comprensionauditiva.htm

CERLAC. (2012). Comportamiento lector y hábitos de lectura . Bogotá: CERLAC.

DANE . (2013). Modulo de habitos de lectura, consumo de libros y asistencia a bibliotecas . Bogotá: DANE.

Enkvist, I. (2000). La educacion en peligro. Madrid, España: Grupo Unison Ediciones.

ENKVIST, I. (2006). Repensar la educación. Madrid, España: Ediciones Internacionales Universitarias, S.A.

Fundalectura. (3 de septiembre de 2014). Fundalectura. Recuperado el 2014, de Fundalectura:http://www.fundalectura.org/?mo dule $=$ proyecto $\& \mathrm{~ms}=33$

Fundalectura, Ministerio de Cultura. (2006). Habitos de lectura, asistencia a bibliotecas y consumo de libros en Colombia. Bogotá: DANE, CERLALC, Camara Colombiana del Libro.

Gallego, J. G. (1955). Pensumes colombianos de enseñanza secundaria. Medellin: Imprenta Departamental de Antioquia. 
Garrido, F. (2000). El buen lector se hace, no nace. Reflexiones sobre lectura y formacion de lectores. México D.F.: Ariel Praticum.

Gray, W. (1958). Enseñanza de la lectura y la escritura. París: UNESCO.

Guzman, R., Varela, S., \& Arce, J. (2010). Referentes para la didactica del lenguaje en el tercer ciclo. Bogotá: Editorial Kimpres Ltda.

Jaramillo, E. (1998). La lectura en voz alta y la recitación en Santafé de Bogotá a fines del siglo XIX. Bogotá : Revista Iberomericana .

Kipling, R. (2004). Cuentos de animales. Bogotá: Secretaria de Cultura Recreación y Deporte y la Secretaría de Educación.

Larrosa, J. (1998). De la experiencia de la lectura: estudios sobre literaturay formación. Barcelona: Ediciones Laertes.

Latorre, A. (2003). La investigacción-acción. Conocer y cambiar la práctica educativa. . Graó: Barcelona .

Lusmidia Alvarado, M. G. (2008). Caracteristicas mas relevantes del paradigma socio-crítico: su aplicación en las investigaciones de investigaciones de educación ambiental y de enseñanza de las ciencias realizadas en el Doctorado de Educación del Instituto Pedagógico de Caracas. Sapiens, Revista Universitaria de Investigación, , 187.

M.E.N., C. (2013). A viva voz, lectura en voz alta. Santiago de Chile: CRA, biblotecas escolares.

Marlen Eizagirre, N. Z. (18 de Junio de 2006). Diccionario de Acción Humanitaria. Obtenido de Diccionario de Acción Humanitaria: http://www.dicc.hegoa.ehu.es/listar/ mostrar/132

Martin, E. (1991). La didáctica de la comprensión auditiva. Barcelona: Revista de didáctica ELE.

Ministerio de Educación Nacional. (2015). Decreto 1038, por el cual se reglamenta la catedra de la paz. Bogotá: Ministerio de Educacion Nacional.

Ministerio de Educación Nacional Argentina. (2009). Proyecto Distrital "Villegas en palabras:. Buenos Aires, Argentina: Plan Nacional de Lectura del Ministerio de Educación Nacional.

Ministerio de Educacion Nacional Colombia. (1998). Lineamientos curriculares de Lengua Castellana. Bogotá: Delfin Ltda.

Morales, O., \& Rincón, a. (2005). Consideraciones pedagógicas para la promoción de la lectura dentro y fuera de la escuela. Revista de Teoría y Didáctica de Las Ciencias Sociales, 195-218.

Ramos, E. (2013). Estrategias para alcanzar nuevos lectores. Serie Bibliotecología y Gestión de Información $N^{\circ}$ 80, Marzo, 2013.

Reyes, Y. (2002). El terror de sexto "B". Bogotá: Alfaguara.

Richardson, J. (2000). Read it aloud! Using literatura in the secondary content classroom . Reading Association .

Sánchez, C. y. (2006). Lectura: una experiencia sublime. Merida: Educere.

Secretaria de Educacion del Distrito Capital Bogotá. (3 de Marzo de 2015). Educación Bogotá. Obtenido de Educación Bogotá: http://www.educacionbogota.edu.co/index. php?option $=$ com_content $\&$ view $=$ article\&id $=14 \&$ Itemid $=273$

Tijanero, A. (2006). El Siglo, La Aurora y la lectura en voz alta en Cuba 1865-18681. Revista Iberoamericana, Vol. LXXII, Núm. 214, 171-183.

Tironi, P. y Molina, A. (2010). Familia y escuela: su influencia en la formacion de lectores para el mañana. fundacion la fuente, Construyendo lectores, 13.

Trelease, J. (2012). Manual de la lectura en voz alta. Bogotá : FUNDALECTURA.

Vega, L. M. (1995). alfabetización, retos y perspectivas. Mexico: UNAM, facultad de psicologia.

Zuluaga, J. E. (1998). Artes de la lectura en la ciudad del Aguila Negra: La lectura en voz alta y la recitacion en Santa Fe de Bogotá a fines del siglo XIX. Revista Iberoamericana. Vol. LXIV Numero 184- 185 , 471- 483. 